\title{
The Effects of Acidosis and Alkalosis on the Metabolism of Glutamine and Glutamate in Renal Cortex Slices
}

\author{
Donald E. Kamm and Gerald L. Strope \\ From the Departments of Medicine, Rochester General Hospital and the \\ University of Rochester School of Medicine and Dentistry, \\ Rochester, New York 14620
}

\begin{abstract}
A B S T R A C T Studies of the metabolism of glutamine and glutamate by renal cortex slices from acidotic, alkalotic, and control rats were performed. $88-95 \%$ of the glutamine and $104-115 \%$ of the glutamate taken up from the medium could be accounted for by the products found. Acidosis increased glutamine uptake and conversion to ammonia, $\mathrm{CO}_{2}$, glucose, lactate, pyruvate, lipid, and protein. The increase in glutamine conversion to ammonia after acidosis could be completely accounted for by the associated increase in its conversion to glucose, glutamate, lactate, and pyruvate. When glutamate metabolism was examined, acidosis did not affect substrate uptake but did increase its conversion to ammonia, glucose, lactate, $\mathrm{CO}_{2}$, and lipid. The increase in ${ }^{14} \mathrm{CO}_{2}$ from $\mathrm{U}-{ }_{-1}{ }^{14} \mathrm{C}$-glutamine and $\mathrm{U}_{-}{ }^{14} \mathrm{C}$-glutamate found with cortex slices from acidotic animals could be explained by the $\mathrm{CO}_{3}$ production calculated to be associated with the enhanced conversion of these substrates to other products during acidosis. ${ }^{14} \mathrm{CO}_{2}$ production from $1,2{ }^{14} \mathrm{C}$-acetate was found to be significantly increased in alkalosis rather than acidosis. These studies suggest that in the rat, the rate at which glutamine is completely oxidized in the Krebs cycle is not a factor regulating renal ammonia production. A comparison of the effects of acidbase status on glutamine and glutamate metabolism suggests that either glutamine transport or glutamine transaminase activity are significantly increased by acidosis.
\end{abstract}

This work was presented in part at the annual meeting of the American Federation for Clinical Research, Atlantic City N. J., May 1969 (Clin. Res. 17: 434) and at the IV International Congress of Nephrology, Stockholm, Sweden, June 1969.

Mr. Strope is a second year student at the University of Rochester School of Medicine and Dentistry.

Received for publication 9 August 1971 and in revised form 20 December 1971.

\section{INTRODUCTION}

The importance of glutamine as the major precursor of renal ammonia production, first described by Van Slyke, Phillips, Hamilton, Archibald, Futcher, and Hiller in 1943 (1), has been well decomuented (2-4). Despite numerous investigations over the past quarter century, the mechanism regulating the increase in ammonia production from glutamine during acidosis remains the subject of continued research. Many control mechanisms have been suggested including: glutamine transport (5), the balance between glutaminase I and glutamine synthetase $(6)$, glutamine transaminase $(7,8)$, mitochondrial oxidation $(9,10)$, PEP-carboxykinase (11-13), and the "redox state" $(14,15)$.

To obtain further information on the mechanism through which acidosis increases renal ammonia production, studies of glutamine uptake and conversion to ammonia, $\mathrm{CO}_{2}$, glucose, and other products by renal cortex slices from acidotic, normal, and alkalotic animals have been made. Because of the importance of glutamate as an intermediate of glutamine metabolism, similar studies have also been performed using this amino acid as substrate. These experiments demonstrate marked effects of acid-base status on glutamine, and to a lesser extent, glutamate metabolism. A comparison of the effects of acidosis on glutamate and glutamine metabolism suggests that either glutamine transport or glutamine transaminase activity are significantly increased during acidosis. Studies of ${ }^{14} \mathrm{CO}_{2}$ production from $\mathrm{U}_{-}{ }^{14} \mathrm{C}$-glutamine, $\mathrm{U}_{-}{ }^{14} \mathrm{C}$-glutamate, and $1,2-{ }^{14} \mathrm{C}$-acetate suggest that in the rat, the increase in renal ammonia production found during acidosis is not secondary to an increase in the rate at which glutamine is completely oxidized in the Krebs cycle.

\section{METHODS}

Feeding protocol. Sprague-Dawley male rats (Holtzman) weighing 250-350 $\mathrm{g}$ were used in all experiments. 
During the $48 \mathrm{hr}$ before an experiment, all animals were deprived of solid food and tube-fed twice a day $15 \mathrm{ml}$ of a $15 \%$ glucose solution containing either $200 \mathrm{~mm} \mathrm{NH} \mathrm{NH}_{4} \mathrm{Cl}$ (acidotic), $200 \mathrm{~mm} \mathrm{NaCl}$ (control), or $200 \mathrm{~mm} \mathrm{NaHCO}_{3}$ (alkalotic). Animals were allowed to drink $75 \mathrm{~mm} \mathrm{NH} \mathrm{NH}_{4} \mathrm{Cl}$ (acidotic), $75 \mathrm{~mm} \mathrm{NaCl}$ (control), or $75 \mathrm{~mm} \mathrm{NaHCO}$ (alkalotic) ad lib.

In vitro studies of renal cortical metabolism. On completion of the various tube-feeding regimens, rats were decapitated, blood was collected for the determination of plasma $\mathrm{CO}_{2}$, and the kidneys were removed. Approximately $150 \mathrm{mg}$ of renal cortical slices, prepared with a Stadie-Riggs microtome, were incubated for $90 \mathrm{~min}$ in Krebs-Ringer bicarbonate medium at $\mathrm{pH} 7.4$ by a method previously described in detail (16). Cortex slices from each animal were incubated in separate flasks containing either no added substrate or $10 \mathrm{~mm}$ glutamine and $\mathrm{U}^{-14} \mathrm{C}$-glutamine $(61,300-135,000 \mathrm{dpm} /$ $\mu$ mole) or $10 \mathrm{~mm}$ glutamate and $\mathrm{U}_{-14}{ }^{14} \mathrm{C}$-glutamate $(46,800$ $117,000 \mathrm{dpm} / \mu$ mole $)$. Glutamine and glutamate were added to the medium from solutions in which the $\mathrm{pH}$ had been adjusted to 7.4 with $0.01 \mathrm{~N} \mathrm{NaOH}$. The amount of $\mathrm{NaCl}$ added to the medium was adjusted so that the sodium concentrations in all media were equivalent. $\mathrm{U}-{ }^{14} \mathrm{C}$-glutamic acid (New England Nuclear Corp., Boston, Mass.) was found to be $97 \%$ pure when chromatographed on Eastman Cellulose Chromagrams (Eastman Kodak Co., Rochester, N. Y.) using a solvent system containing isopropyl alcohol, formic acid, and water $(75 / 12.5 / 12.5, \mathrm{v} / \mathrm{v})(17)$.

When $\mathrm{U}-{ }^{14} \mathrm{C}$-glutamine (New England Nuclear Corp.) was examined in the same chromatographic system as $U-{ }^{14} \mathrm{C}$. glutamate (17) it was found to be $90-93 \%$ pure. The main contaminant of $\mathrm{U}-^{14} \mathrm{C}$-glutamine was pyrollidone carboxylate, which contained $4-7 \%$ of the radioactivity. Glutamate contained $0.3-1.0 \%$, and other amino acids, a total of $1-2 \%$ of the radioactivity. When $\mathrm{U}_{-}{ }^{14} \mathrm{C}$-glutamine was examined in the thin-layer system just described with the modification that solvent 1 was used in both directions, it was found that $4-5 \%$ of the radioactivity present in the glutamine spot after migration in the first direction appeared in the pyrollidone carboxylate spot when migrated in the second direction. Thus, the purity of $\mathrm{U}_{-1}^{14} \mathrm{C}$-glutamine present in the incubation flask before exposure to the chromatographic solvents is probably about $95 \%$. To determine the impurities present as organic acids, $\mathrm{U}_{-14}{ }^{14} \mathrm{C}$-glutamine was also examined in the thin-layer system described by Whereat, Snydman, and Barness (18). Using this method, pyrollidone carboxylate contained $3.5-4.0 \%$, lactate + pyruvate $0.1-0.2 \%$ and all other organic acids $0.6-0.8 \%$ of the radioactivity. The radioactivity isolated in pyrollidone carboxylate was similar before and after incubation with slices. This finding is consistent with the observations of Weil-Malherbe and Krebs (19) in which pyrollidone carboxylate was not found to be metabolized by renal cortex slices. In the present studies, therefore, the radioactivity found in pyrollidone carboxylate at the end of an experiment was not considered a product of glutamine metabolism by cortex slices.

At the end of the $90 \mathrm{~min}$ incubation period, separate portions of the medium were deproteinized with $5 \%$ zinc sulfate heptahydrate and $0.3 \mathrm{~N}$ barium hydroxide, $6 \%$ perchloric acid, or 5\% trichloroacetic acid (TCA) for later analyses. Determinations for ammonia and ${ }^{14} \mathrm{CO}_{2}$, and extraction of lipids were started immediately from untreated medium. Glucose was determined from the zinc sulfatebarium hydroxide filtrates using a glucose oxidase technique (20). Lactate and pyruvate were determined enzymatically in neutralized perchlorate filtrates $(21,22)$. Me- dium ammonia concentration was determined in duplicate by the Conway microdiffusion method (23). The ammonia found in glutamine medium incubated without slices was subtracted in the calculation of ammonia production.

Glutamate concentration was determined in the TCA filtrates using the fluorometric procedure described by Graham, Werman, and Aprison (24). Glutamine was determined in TCA or perchlorate filtrates, or in media diluted with $0.2 \mathrm{M}$ acetate buffer at $\mathrm{pH} 4.8$ and kept frozen overnight, by a variation of the glutaminase method described by Addae and Lotspeich (25). In this analysis, $1 \mathrm{ml}$ of diluted medium or medium filtrate was added to $1 \mathrm{ml}$ of $0.2 \mathrm{M}$ acetate buffer containing $1 \mathrm{U}$ of glutaminase (Sigma Chemical Co., St. Louis, Mo.). A similar portion was added to $1 \mathrm{ml}$ of $0.2 \mathrm{M}$ acetate buffer without glutaminase. The ammonia found in this sample was subtracted in the calculation of glutamine concentration. After incubation for $1 \mathrm{hr}$ at $37^{\circ} \mathrm{C}, 1 \mathrm{ml}$ of the phenol reagent $(20 \mathrm{~g}$ phenol plus $0.1 \mathrm{~g}$ nitroferricyanide/ liter) was added, followed by $1 \mathrm{ml}$ of the alkaline hypochlorite solution ( $10 \mathrm{~g} \mathrm{NaOH}$ plus $0.84 \mathrm{~g}$ sodium hypochlorite dissolved in 1 liter of $\mathrm{pH} 120.2 \mathrm{M}$ sodium phosphate buffer). After incubation at room temperature for $30 \mathrm{~min}$, the samples were read on a Gilford spectrophotometer (Gilford Instrument Laboratories, Inc., Oberlin, Ohio) at $625 \mathrm{~m} \mu$. Recovery studies demonstrated complete recovery of glutamine added to media, or to TCA and perchlorate filtrates of media, obtained after incubation with slices from acidotic, control, or alkalotic animals.

Since the glutaminase reaction is inhibited by glutamate, medium from the glutamate studies was passed through a column containing an anion exchanger (AG1-X8, Bio-Rad Laboratories, Richmond, Calif.) to separate glutamate from glutamine. Because of the low glutamine and high $\mathrm{NH}_{4}+$ in the eluate, glutamine could not be accurately determined with the glutaminase/indolphenol method described above. Instead, glutamine was first converted to glutamate by acid hydrolysis (26) and glutamate determined with the fluorometric assay already described. Glutamine standards were also assayed as glutamate after similar treatment. Glutamine and glutamate utilization by cortex slices was determined by comparing substrate concentration present at the end of incubation with that found in medium incubated at $37^{\circ} \mathrm{C}$ without slices.

To determine the conversion of ${ }^{14} \mathrm{C}$-substrates to $\mathrm{CO}_{2}$, $1 \mathrm{ml}$ of untreated medium was placed in a $25 \mathrm{ml}$ Erlenmeyer flask and the medium in the stoppered flask was acidified with $0.2 \mathrm{ml}$ of $10 \mathrm{~N} \mathrm{H}_{2} \mathrm{SO}_{4}$. The evolved $\mathrm{CO}_{2}$ was collected, during $3 \mathrm{hr}$ of gentle shaking, in a polypropylene center well (Kontes Glass Co., Vineland, N. J.) containing $0.2 \mathrm{ml}$ of phenethylamine. The center well was then dropped into a scintillation vial and counted in a Nucear-Chicago Mark I liquid scintillation counter (Nuclear-Chicago, Des Plaines, Ill.) after the addition of $15 \mathrm{ml}$ of the liquid scintillation counting fluid described by Gupta (27). The radioactivity found in a blank ${ }^{14} \mathrm{CO}_{2}$ determination made with medium incubated without slices was subtracted in the calculation of ${ }^{14} \mathrm{CO}_{2}$ production. A correction was made for the $\mathrm{CO}_{2}$ calculated to be present in the gas phase of the incubation flask. This correction was based on the measured flask volume, an assumed molar gas volume at $37^{\circ} \mathrm{C}$ of $25.4 \mu \mathrm{l} / \mu$ mole and studies of medium $\mathrm{P}_{\mathrm{co}_{2}}$ and total $\mathrm{CO}_{2}$ made anaerobically at the end of incubation (see Appendix). Using the calculated gas phase $\mathrm{CO}_{2}$ in the determination of total flask $\mathrm{CO}_{2}$, the recovery in $\mathrm{CO}_{2}$ of $\mathrm{NaH}^{14} \mathrm{CO}_{3}$ added to eight flasks containing Krebs-bicarbonate buffer was $105.4 \%$ (range $100-109 \%$ ). 
The conversion of ${ }^{14} \mathrm{C}$-substrates to glucose was determined from the specific activity of glucose isolated as the phenylosazone derivative and combusted using a modification of the in-vial combustion method described by Gupta (27). The glucosazone crystals were dissolved in about $2.5 \mathrm{ml}$ of near boiling ethanol. $2 \mathrm{ml}$ of this solution were pipetted into a tared tube, and $0.1 \mathrm{ml}$ into a platinum-irridium wire stand and cup. This stand had previously been placed in a scintillation vial and contained a cotton pellet and siliconized lens paper blackened with India ink. After the vial had been dried for at least $4 \mathrm{hr}$ in a vented oven at $60^{\circ} \mathrm{C}$, phenethylamine, $0.1 \mathrm{ml}$, was added to a glass fiber disc (Reeve Angel $934 \mathrm{AH} ; \mathrm{H}$. Reeve Angel \& Co., Clifton, N. J.) previously placed in the vial. The vial was then flushed with $100 \% \mathrm{O}_{2}$ and capped tightly with a foil-lined cap. The lens paper was then ignited by focusing a strong beam of light from a projector lamp on the blackened spot. $3 \mathrm{hr}$ later, the vial was opened, $15 \mathrm{ml}$ of counting solution was introduced; and the vial was tightly recapped. After allowing at least $3 \mathrm{hr}$ for the carbamate formed between the $\mathrm{CO}_{2}$ and phenethylamine to dissolve, the samples were counted in a liquid scintillation counter. The amount of material combusted was calculated from the osazone found in the dried tared tube. When the osazone was prepared with cold glucose and $\mathrm{U}-{ }^{14} \mathrm{C}$-glucose, recovery of the isotope in the osazone was $96-104 \%$. No radioactivity was recovered in the osazone when the derivative was prepared with cold glucose in the presence of $1,2-{ }^{14} \mathrm{C}$-pyruvate, $\mathrm{U}-{ }^{14} \mathrm{C}$-glutamine medium incubated without slices, or $\mathrm{U}-{ }^{14} \mathrm{C}$-glutamate medium incubated without slices.

In the ${ }^{14} \mathrm{C}$-substrate studies summarized in Table $\mathrm{I}$ all of the data, except those for glucose production, were calculated according to equation 1 , and are presented as $\mu$ moles of substrate in product.

$\mu$ moles of substrate in product

$$
=\frac{\mathrm{dpm} \text { in product per gram dry weight }}{\mathrm{dpm} \text { per } \mu \text { mole of substrate }}
$$

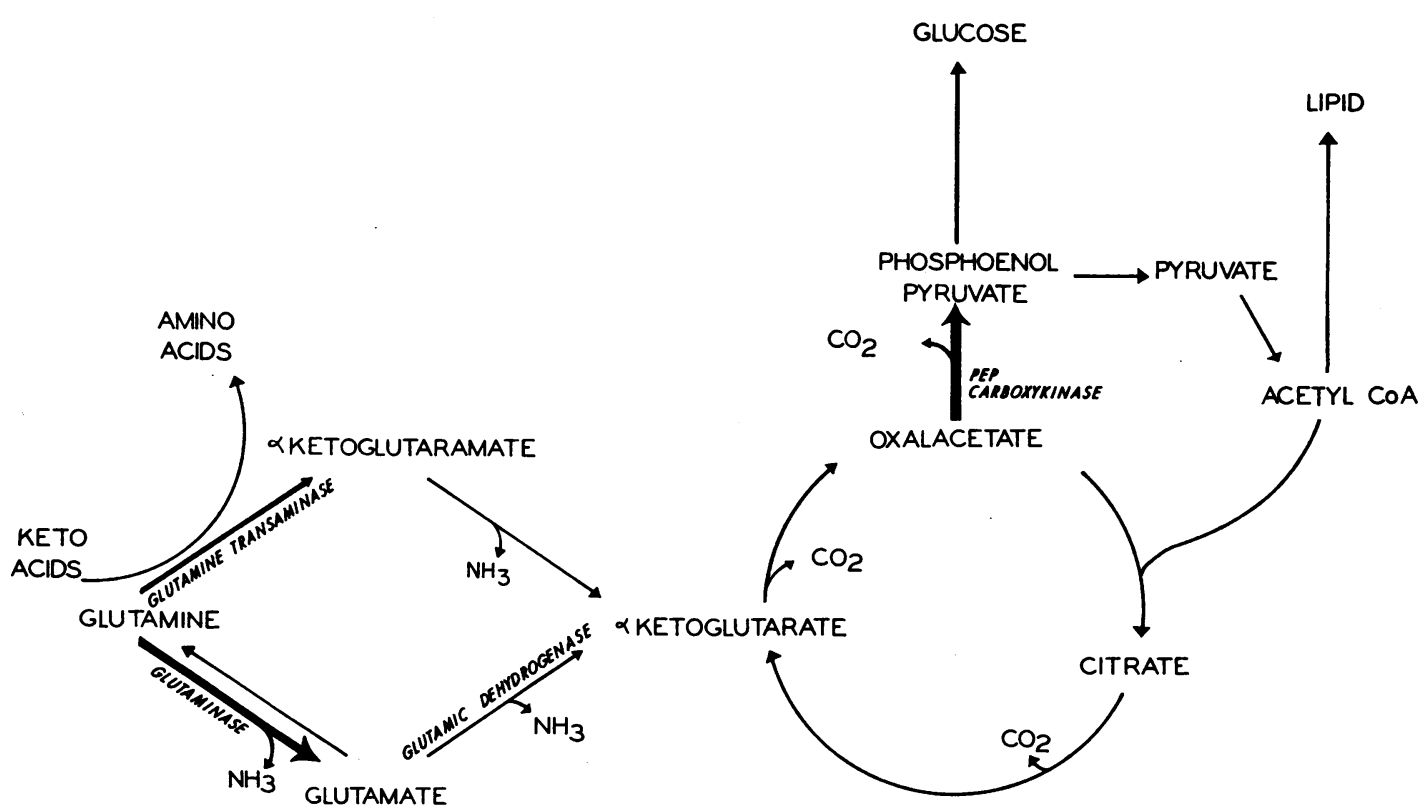

FIGURE 1 Pathways of glutamine and glutamate metabolism in renal cortex.
The $\mu$ moles of glucose formed from substrate were calculated by equation 2 . This calculation allows glucose production from glutamine and glutamate, determined with ${ }^{14} \mathrm{C}$, to be directly compared with glucose production determined with glucose oxidase. Equation 2 is based on the assumption that only three of the five carbons of uniformly labeled glutamine or glutamate are converted to phosphoenolpyruvate (Fig. 1), and that the effective specific activity of the uniformly labeled glutamine and glutamate converted to glucose is therefore only $\frac{3}{5}$ the specific activity of the five carbon compound. Thus, the $\mu$ moles of phosphoenolpyruvate, and therefore of glutamine or glutamate, from which the glucose was derived is equal to the $\mu$ moles of substrate found in glucose according to equation 1 multiplied by $5 / 3$. $2 \mu$ moles of phosphoenolpyruvate are required for the synthesis of 1 $\mu$ mole of glucose. Thus :

$\mu$ moles of glucose formed from substrate

$$
=\mu \text { moles of substrate in glucose } \times \frac{5}{3} \times \frac{1}{2}
$$

For extraction of lipids, slices were placed in a $2: 1$ chloroform-methanol mixture. The first crude extract was decanted and fresh chloroform-methanol added. The two crude extracts were combined and treated as described by Folch, Lees, and Sloane-Stanley (28). A portion of the final solution was placed in a liquid scintillation vial and counted after evaporation of the solvent. To determine the amount of ${ }^{14} \mathrm{C}$-substrate converted to protein, the tissue remaining after the lipid extraction was homogenized and purified as described by Bignall, Elebute, and Lotspeich (29) with the exception that the final solubilization of the protein was in $1 \mathrm{~N} \mathrm{NaOH}$ instead of hyamine. Protein was determined by the method of Lowry, Rosebrough, Farr, and Randall (30). $\frac{1}{2} \mathrm{ml}$ of the protein solution was pipetted into a scintillation vial, neutralized with $\mathrm{HCl}$, and counted in Bray's solution containing 5\% Cab-O-Sil (Cabot Corp., Boston, Mass.). In our earlier experiments the radioactivity present in medium protein and lipid was determined and found not to be

Effects of Acid-Base Status on Renal Glutamine and Glutamate Metabolism 
TABLE I

Effect of Acidosis and Alkalosis on Glutamate and Glutamine Metabolism in Renal Cortical Slices

\begin{tabular}{|c|c|c|c|c|c|c|c|c|c|c|}
\hline \multirow[b]{2}{*}{ Glutamate Studies } & \multicolumn{2}{|l|}{ Units } & \multicolumn{2}{|l|}{ Alkalotic } & \multicolumn{3}{|c|}{ Control } & \multicolumn{3}{|c|}{ Acidotic } \\
\hline & & & & & & & & & & \\
\hline Substrate uptake & $\mu$ moles per $\mathrm{g}$ dry wt & 718 & \pm 38 & (33) & 728 & \pm 43 & $(32)$ & 797 & \pm 49 & (26) \\
\hline \multicolumn{11}{|l|}{ Substrate conversion to: } \\
\hline Ammonia & $\mu$ moles of product $\ddagger$ per $\mathrm{g}$ dry wt & 183 & $\pm 7.3^{* *}$ & (33) & 319 & \pm 8.1 & (33) & 436 & $\pm 9.6^{* *}$ & (27) \\
\hline Glucose & & 108 & $\pm 4.1^{* *}$ & (33) & 154 & \pm 4.5 & (33) & 204 & $\pm 7.1^{* *}$ & (27) \\
\hline Glutamine & & 181 & $\pm 23^{* *}$ & (13) & 53 & \pm 6.8 & (13) & 22.9 & $\pm 4.0^{* *}$ & (13) \\
\hline Lactate & & 15.7 & \pm 1.2 & (29) & 18.9 & \pm 1.6 & (24) & 28.2 & $\pm 3.8^{*}$ & (24) \\
\hline Pyruvate & & 2.62 & $2 \pm 0.33$ & $(10)$ & 2.71 & $71 \pm 0.42$ & $(10)$ & 2.45 & $45 \pm 0.49$ & (8) \\
\hline Glucose & $\begin{array}{l}\mu \text { moles of glucose from glutamate§ } \\
\text { per g dry wt }\end{array}$ & 87.6 & $\pm 3.4^{* *}$ & (33) & 131 & \pm 4.8 & $(33)$ & 192 & $\pm 6.1^{* *}$ & (27) \\
\hline Carbon dioxide & $\begin{array}{l}\mu \text { moles of glutamate } \delta \text { in product } \\
\text { per g dry wt }\end{array}$ & 349 & \pm 10.2 & $(33)$ & 367 & \pm 11.1 & $(33)$ & 401 & $\pm 10.3^{*}$ & $(27)$ \\
\hline Alanine & & 16.0 & \pm 1.5 & (12) & 16.8 & $3 \pm 0.7$ & (13) & 14.9 & \pm 1.4 & (11) \\
\hline Glycine & & & $<10$ & $(12)$ & & $<10$ & (13) & & $<10$ & (11) \\
\hline Serine & & 22 & \pm 3.8 & (12) & 22.6 & \pm 2.6 & (13) & 18.5 & \pm 2.4 & (11) \\
\hline \multicolumn{11}{|l|}{ Slice } \\
\hline Protein & & 16.2 & $\pm 0.66^{*}$ & $(12)$ & 14.5 & \pm 0.39 & $(12)$ & 15.6 & \pm 0.53 & (10) \\
\hline Nonprotein & & 106 & \pm 4.85 & (5) & 91.4 & \pm 3.12 & $(5)$ & 115 & \pm 3.51 & (5) \\
\hline Lipid & & 2.8 & \pm 0.10 & (12) & 3.2 & \pm 0.11 & $(12)$ & 5.0 & $\pm 0.16^{* *}$ & * (10) \\
\hline \multicolumn{11}{|l|}{ Glutamine Studies } \\
\hline Substrate uptake & $\mu$ moles per g dry wt & 856 & $\pm 44^{*}$ & $(31)$ & 1031 & \pm 58 & $(33)$ & 1559 & $\pm 73^{* *}$ & (31) \\
\hline \multicolumn{11}{|c|}{ Substrate conversion to: } \\
\hline Ammonia & $\mu$ moles of productf per $\mathrm{g}$ dry wt & 819 & $\pm 29^{* *}$ & $(25)$ & 1186 & \pm 31.1 & $(26)$ & $1779=$ & $\pm 52.5^{* *}$ & (25) \\
\hline Glucose & & 70 & $\pm 5.1^{* *}$ & (23) & 136 & \pm 6.3 & $(26)$ & $241=$ & $\pm 9.6^{* *}$ & $(25)$ \\
\hline Glutamate & & 264 & \pm 18.2 & (19) & 291 & \pm 18.2 & (19) & $402=$ & $\pm 14.2^{* *}$ & * (19) \\
\hline Lactate & & 19.0 & $\pm 1.4^{*}$ & $(32)$ & 24.2 & \pm 1.7 & (29) & 53.2 & $\pm 4.9^{* *}$ & $(24)$ \\
\hline Pyruvate & & 3.64 & $4 \pm 0.46$ & (13) & 4.22 & $2 \pm 0.66$ & $(13)$ & 7.07 & $7 \pm 1.3^{*}$ & $(11)$ \\
\hline Glucose & $\begin{array}{l}\mu \text { moles of glucose from glutamine } \S \\
\text { per g dry wt }\end{array}$ & 49.6 & $\pm 1.9^{* *}$ & $(25)$ & 98.6 & \pm 3.1 & $(26)$ & $197=$ & $\pm 9.2^{* *}$ & $(25)$ \\
\hline Carbon dioxide & $\begin{array}{l}\mu \text { moles of glutamine } \$ \text { in product } \\
\text { per g dry wt }\end{array}$ & 268 & $\pm 7.7^{* *}$ & $(25)$ & 336 & \pm 9.9 & $(26)$ & 429 & $\pm 16.2^{* *}$ & (25) \\
\hline Alanine & & 16.3 & \pm 2.5 & $(7)$ & 13.2 & \pm 2.4 & $(7)$ & 19.9 & \pm 2.0 & (6) \\
\hline Aspartate & & 20.0 & \pm 3.3 & (7) & 18.1 & \pm 2.4 & (6) & 16.0 & \pm 2.4 & (6) \\
\hline Glycine & & 25.0 & \pm 1.7 & (7) & 24.4 & \pm 4.5 & (7) & 26.4 & \pm 5.6 & (6) \\
\hline Serine & & 15.3 & \pm 1.5 & (7) & 11.9 & \pm 1.4 & (7) & 13.7 & \pm 3.1 & (6) \\
\hline \multicolumn{11}{|l|}{ Slice } \\
\hline Protein & & 7.38 & $3 \pm 0.31$ & (13) & 7.8 & \pm 2.53 & $(13)$ & 12.8 & $\pm 0.35^{* *}$ & * (12) \\
\hline Nonprotein & & 111 & \pm 6.0 & (5) & 96.8 & \pm 3.84 & $(5)$ & 113 & \pm 5.36 & (5) \\
\hline Lipid & & 1.25 & $\pm 0.05^{* *}$ & (14) & 1.6 & \pm 0.05 & (14) & $3.22=$ & $2 \pm 0.15^{* *}$ & $(12)$ \\
\hline
\end{tabular}

* Significantly different from control ${ }^{*} P<0.05,{ }^{* *} P<0.01$. $\ddagger$ Determined by measurement of products.

§ Determined with ${ }^{14} \mathrm{C}$.

significantly different from background. In this report, therefore, only the incorporation of ${ }^{14} \mathrm{C}$-substrates into tissue protein and lipid has been considered.

The incorporation of ${ }^{14} \mathrm{C}$-substrates into medium amino acids was determined by thin-layer chromatography using the bidirectional solvent system described by White (17) on Eastman Cellulose Chromagrams. In preliminary studies, the only amino acids produced from ${ }^{14} \mathrm{C}$-glutamine and -glutamate in renal cortex slices in significant amounts were alanine, aspartate acid, glutamate, glutamine, glycine, and serine. The sensitivity of this method is not sufficient to rule out conversion of glutamate and glutamine to other amino acids in amounts less than $10 \mu$ moles of substrate $/ g$ dry weight. When glutamate was substrate, its incorporation into aspartate could not be determined because of overlap of the aspartate spot with the large glutamate spot. After location of the amino acids by cochromatography, the appropriate spots were cut out and counted in liquid scintillation fluid containing $10.5 \mathrm{~g}$ PPO, $0.45 \mathrm{~g}$ POPOP, and $15 \mathrm{~g}$ naphthalene made up to $1500 \mathrm{ml}$ with dioxane, to which water was added to give a total volume of $1800 \mathrm{ml}$. The loss of counts secondary to the ninhydrin used for 
identification by cochromatography varied from 4 to $16 \%$ and was predictable for a given amino acid. All samples were counted long enough to give $5 \%$ accuracy. In several experiments, the incorporation of ${ }^{14} \mathrm{C}$-substrates into the nonprotein components of the slice was also determined. For this determination, after incubation, slices were blotted briefly on damp filter paper and homogenized in $0.5 \mathrm{ml}$ of $6 \%$ perchloric acid. A portion of the neutralized perchlorate filtrate was counted in the liquid scintillation fluid described above for use in the analysis of ${ }^{14} \mathrm{C}$ in amino acids. With the exception of glucose production, the results of the ${ }^{14} \mathrm{C}$ substrate studies are expressed as $\mu$ moles of substrate converted to products per gram dry weight. In those studies in which the incorporation of ${ }^{14} \mathrm{C}$-substrate into slices was determined, the dry weight were estimated from accurately determined wet weights and the wet weight:dry weight ratio of cortex slices from the same animal incubated without added substrate.

\section{RESULTS}

The observations on glutamate and glutamine metabolism summarized in Table I were derived from 24 experiments. Each experiment included acidotic, control, and alkalotic animals, with 3-7 animals per group. All of the products listed in the table were not determined in each experiment. The production of glucose and ammonia by slices incubated without added substrate has been subtracted in the calculation of net glucose and ammonia production from glutamine and glutamate. The production of glutamaine, glutamate, lactate, and pyruvate by slices incubated without added substrate was insignificant. The observations on the incorporation of ${ }^{14} \mathrm{C}$-substrates into products are based only on the analysis of flasks containing $10 \mathrm{~mm}$ glutamine and $\mathrm{U}-{ }^{14} \mathrm{C}$-glutamine or 10 mM glutamate and $\mathrm{U}_{-}{ }^{14} \mathrm{C}$-glutamate.

Glutamate studies. The effects of in vivo acid-base status on the metabolism of glutamate in renal cortical slices are summarized in the upper part of Table I. The mean $\pm \mathrm{sE}$ is given and the number of observations is shown in parentheses. Glutamate uptake was $728 \pm 43$ $\mu$ moles/g dry weight with slices from control animals and was not significantly affected by acid-base status. It can be seen that most of the glutamate taken up was converted to $\mathrm{CO}_{2}$, glucose, and glutamine with smaller amounts appearing in lactate, pyruvate, alanine, serine, lipid, and protein. Acidosis increased the conversion of glutamate to ammonia, glucose, and lipid $(P<0.01)$, probably increased conversion to $\mathrm{CO}_{2}$ and lactate $(P<$ $0.05)$, and decreased the production of glutamine $(P<$ $0.01)$. Alkalosis significantly decreased ammonia and glucose production $(P<0.01)$, and increased the conversion of glutamate to glutamine $(P<0.01)$ and protein $(P<0.05)$. Glucose production determined from the incorporation of $\mathrm{U}_{-}{ }^{14} \mathrm{C}$-glutamate into glucose correlated in a linear manner with glucose production determined with glucose oxidase. (Glucose production $\left[{ }^{14} \mathrm{C}\right]$
$=0.84$ glucose production [glucose oxidase] $+4.0, \mathrm{r}=$ 0.84.])

Glutamine studies. The effects of in vivo acid-base status on the metabolism of glutamine in renal cortical slices are shown in the lower part of Table I. Glutamine uptake was significantly greater than glutamate uptake with slices from control animals $(P<0.01)$ and was, in addition, markedly influenced by acid-base status. With slices from acidotic animals glutamine uptake increased to $1559 \mu \mathrm{moles} / \mathrm{g}$ dry weight, a value almost double the glutamate uptake of $797 \mu$ moles. Conversely, with slices from alkalotic animals, glutamine uptake dropped to 819 mmoles, a value approaching the glutamate uptake of 719 $\mu$ moles. Most of the glutamine taken up from the medium was converted to $\mathrm{CO}_{2}$, glucose, glutamate, and lactate with smaller amounts appearing in pyruvate, alanine, aspartate, glycine, serine, lipid, and protein. Acidosis significantly enhanced the conversion of glutamine to ammonia, glucose, lactate, $\mathrm{CO}_{2}$, lipid, and protein $(P<$ $0.01)$ and probably increased pyruvate production $(P<$ $0.05)$. Overall, the effects of alkalosis on glutamine metabolism were opposite those of acidosis.

Glucose production determined from the incorporation of $\mathrm{U}_{-}{ }^{14} \mathrm{C}$-glutamine in glucose correlated in a linear manner with glucose production determined with glucose oxidase (glucose production $\left[{ }^{14} \mathrm{C}\right]=0.81$ glucose production [glucose oxidase] $-4.0, r=0.94)$. With either method, the effects of acid-base status on gluconeogenesis were found to be more marked in the glutamine than in the glutamate studies.

Substrate recovery. In Table II the data, which had been expressed as $\mu$ moles of product, or $\mu$ moles of substrate in product in Table $I$, have all been expressed in a common unit, $\mu$ moles of substrate carbon or nitrogen, so that they may be summed and the recovery of substrate carbon or nitrogen in products calculated. The total recovery of glutamate carbon and nitrogen observed was $104-115 \%$ and $79-98 \%$, respectively, of the glutamate taken up from the media. The recovery of glutamine carbon and nitrogen in products was $88-95 \%$ and $82-87 \%$, respectively.

${ }^{14} \mathrm{CO}$, production from $U_{-}{ }^{14} \mathrm{C}$-glutamine, $U_{-}{ }^{14} \mathrm{C}$-glutamate, and $1,2-{ }^{15} \mathrm{C}$-acetate. The conversion of glutamine and glutamate to products along the pathways shown in Fig. 1 is associated with predictable quantities of $\mathrm{CO}_{2}$ production. Fig. 2 is an analysis of the contribution of the calculated product associated ${ }^{14} \mathrm{CO}_{2}$ production to tota ${ }^{14} \mathrm{CO}_{2}$ production, using data derived from the values given in Table I. The total height of the bars represents total ${ }^{14} \mathrm{CO}_{2}$ production. The upper part of each bar represents the ${ }^{14} \mathrm{CO}_{2}$ calculated to be produced in association with the conversion of glutamate or glutamine to glucose, pyruvate, lipid, protein, and amino acids. When the ${ }^{14} \mathrm{CO}_{2}$ associated with the formation of these products is sub- 
TABLE II

Recovery of Glutamate and Glutamine Carbon and Nitrogen in Products*

\begin{tabular}{|c|c|c|c|c|c|c|c|c|c|c|c|c|}
\hline & \multicolumn{6}{|c|}{ Glutamate studies } & \multicolumn{6}{|c|}{ Glutamine studies } \\
\hline & \multicolumn{2}{|c|}{ Alkalosis } & \multicolumn{2}{|c|}{ Control } & \multicolumn{2}{|c|}{ Acidosis } & \multicolumn{2}{|c|}{ Alkalosis } & \multicolumn{2}{|c|}{ Control } & \multicolumn{2}{|c|}{ Acidosis } \\
\hline & Carbon & Nitrogen & Carbon & Nitrogen & Carbon & Nitrogen & Carbon & Nitrogen & Carbon & Nitrogen & Carbon & Nitrogen \\
\hline $\mathrm{NH}_{3}$ & & 183 & & 319 & & 436 & & 928 & & 1268 & & 1860 \\
\hline $\mathrm{CO}_{2}$ & 1745 & & 1835 & & 2005 & & 1340 & & 1680 & & 2145 & \\
\hline Glucose & 650 & & 920 & & 1225 & & 420 & & 815 & & 1445 & \\
\hline Lactate & 50 & & 55 & & 85 & & 55 & & 70 & & 160 & \\
\hline Pyruvate & 10 & & 10 & & 5 & & 10 & & 10 & & 20 & \\
\hline Glutamine & 905 & 362 & 265 & 106 & 115 & 46 & & & & & & \\
\hline Glutamate & & & & & & & 1320 & 264 & 1455 & 292 & 2010 & 402 \\
\hline Alanine & 70 & 23 & 75 & 25 & 70 & 23 & 80 & 28 & 65 & 22 & 90 & 30 \\
\hline Aspartate & & & & & & & 130 & 34 & 90 & 24 & 100 & 26 \\
\hline Glycine & & & & & & & 125 & 64 & 130 & 66 & 145 & 74 \\
\hline Serine & 80 & 27 & 85 & 28 & 75 & 25 & 65 & 22 & 60 & 20 & 75 & 26 \\
\hline \multicolumn{13}{|l|}{ Slice } \\
\hline Protein & 80 & 20 & 75 & 19 & 80 & 20 & 35 & 10 & 40 & 10 & 65 & 16 \\
\hline Nonprotein & 530 & 90 & 455 & 77 & 575 & 97 & 490 & 102 & 485 & 101 & 565 & 118 \\
\hline Total recovery & 4120 & 705 & 3775 & 574 & 4235 & 647 & 4070 & 1452 & 4900 & 1803 & 6820 & 2552 \\
\hline Observed uptake & 3590 & 718 & 3640 & 728 & 3985 & 797 & 4280 & 1716 & 5155 & 2062 & 7795 & 3118 \\
\hline \% Recovery & 115 & 98 & 104 & 79 & 106 & 81 & 95 & 85 & 95 & 87 & 88 & 82 \\
\hline
\end{tabular}

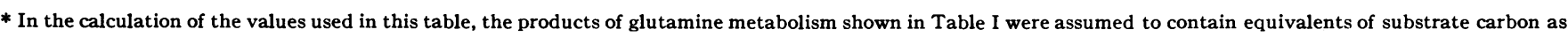

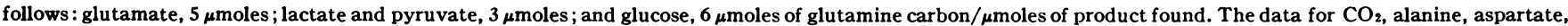

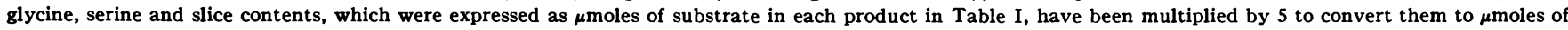

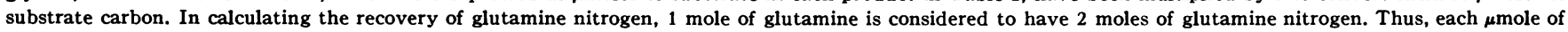

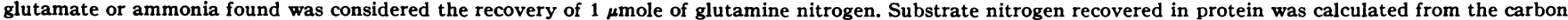

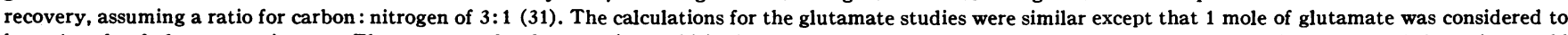

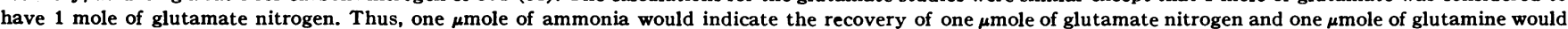

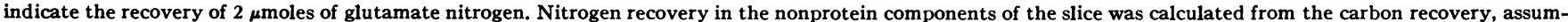

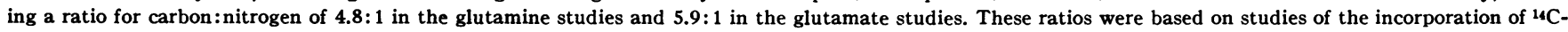

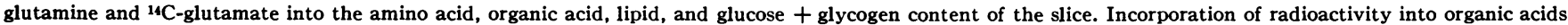

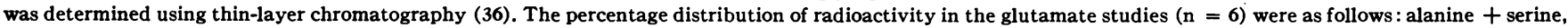

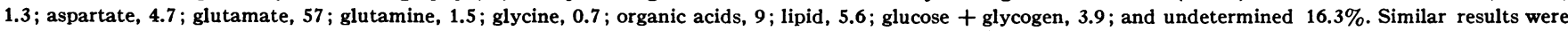
obtained in the glutamine studies except that glutamate contained 44, glutamine 19 , and the undetermined fraction $10.3 \%$ of the radioactivity.

tracted from the total ${ }^{14} \mathrm{CO}_{2}$, the remainder, represented by the lower hatched portion of the bar is a measure of the extent to which the substrate is completely oxidized to $\mathrm{CO}_{2}$ and presumably reflects substrate oxidation in the Krebs cycle. This figure demonstrates graphically the small changes in $\mathrm{U}_{-}{ }^{14} \mathrm{C}$-glutamate conversion to ${ }^{14} \mathrm{CO}_{2}$ and large changes in $\mathrm{U}_{-}{ }^{14} \mathrm{C}$-glutamine conversion to ${ }^{14} \mathrm{CO}_{2}$ already described in Table I, which occur following acidosis and alkalosis. When the product associated ${ }^{14} \mathrm{CO}_{2}$ is subtracted from total ${ }^{14} \mathrm{CO}_{2}$ production, the remaining ${ }^{14} \mathrm{CO}_{2}$ production is unaffected by acid-base status. These observations suggest that the complete oxidation of glutamine and glutamate to $\mathrm{CO}_{2}$ in the Krebs cycle is not increased by acidosis.

Since acetate is oxidized in the Krebs cycle but would not give rise to $\mathrm{CO}_{2}$ when converted to other products, studies of the effects of acid-base status on ${ }^{14} \mathrm{CO}_{2}$ production from $1,2-{ }^{14} \mathrm{C}$-acetate were also performed (Fig. 3). Each point in Fig. 3 represents three to six observations on ${ }^{14} \mathrm{CO}_{2}$ production by cortex slices from different animals incubated in Krebs-Ringer bicarbonate medium containing $25 \mathrm{~mm}$ and $1,2-{ }^{14} \mathrm{C}$-acetate $(12,200-110,000 \mathrm{dpm} /$ $\mu$ mole). Also shown is the mean $\pm \mathrm{SE}$ for all observations with alkalotic $(n=26)$, control $(n=27)$, and acidotic $(n=24)$ animals. With slices from alkalotic animals, the conversion of ${ }^{14} \mathrm{C}$-acetate to ${ }^{14} \mathrm{CO}_{2}$ was $774 \pm 40$ $\mu$ moles of $\mathrm{CO}_{2} / \mathrm{g}$ dry weight, a value significantly higher $(P<0.05)$ than the values of $660 \pm 28$ and $642 \pm 44$ found with slices from control and acidotic animals, respectively. With the exception of one experiment, $\mathrm{CO}_{2}$ production was higher after alkalosis, and lower after acidosis, when compared with the data from control animals. To determine if the results shown in Fig. 3 were related to the method employed, in which flasks were opened at the end of incubation, two similar experiments, not shown in Fig. 3, were done in which the conversion of $1,2-{ }^{14} \mathrm{C}$-acetate to ${ }^{14} \mathrm{CO}_{2} \quad(24,900-32,800$ $\mathrm{dpm} / \mu$ mole) was determined without opening the flasks. At the end of incubation, $0.2 \mathrm{ml}$ of phenethylamine was injected through the rubber stopper into a center well and $1 \mathrm{ml}$ of $10 \mathrm{~N} \mathrm{H}_{2} \mathrm{SO}_{4}$ was injected into the medium. ${ }^{14} \mathrm{CO}_{2}$ was then determined as described under Methods. Recovery of $\mathrm{NaH}^{14} \mathrm{CO}_{3}$ added to control flasks was 98$103 \%$. $\mathrm{CO}_{2}$ production from acetate with cortex slices 




FIgURE 2 The effect of in vivo acid-base status on the conversion of $\mathrm{U}-{ }^{14} \mathrm{C}$-glutamate and $\mathrm{U}^{-14} \mathrm{C}$-glutamine to ${ }^{14} \mathrm{CO}_{2}$. The data are expressed as $\mu$ moles of substrate carbon in $\mathrm{CO}_{2}$ per gram dry weight (GDW) per $90 \mathrm{~min}$. The total height of the columns represents total conversion of $\mathrm{U}^{14} \mathrm{C}$ glutamate or $\mathrm{U}^{14} \mathrm{C}$-glutamine to ${ }^{14} \mathrm{CO}_{2}$. The upper segment of each bar represents the ${ }^{14} \mathrm{CO}_{2}$ calculated to be produced as a result of the conversion of substrate to other products.

from normal animals was $542 \pm 19 \mu$ moles/g dry weight per $90 \min (\mathrm{n}=9)$. Acidosis reduced $\mathrm{CO}_{2}$ production from acetate to $462 \pm 25(\mathrm{n}=9, P<0.05)$ and alkalosis increased it to $607 \pm 7.6(\mathrm{n}=11, P<0.02)$. With either method, it appears that acetate conversion to $\mathrm{CO}_{2}$, unlike that of glutamine, is stimulated by alkalosis rather than acidosis.

Relation between glutamine conversion to ammonia and its conversion to other products. In Fig. 4 we have attempted to determine the extent to which the products of glutamine metabolism associated with ammonia production have been measured. The values shown have been derived from the data presented in Table I. In this analysis it has been assumed that all of the products have been derived from glutamine. Conversion of 1 mole of glutamine to a product not containing nitrogen is assumed to give rise to 2 moles of ammonia ; conversion to 1 mole of the amino acids measured in this study is assumed to result in the production of 1 mole of ammonia. The predicted $\mathrm{NH}_{3}$, shown on the ordinate, and graphed for the studies with slices from alkalotic, control, and acidotic animals, is plotted against the observed $\mathrm{NH}_{8}$ production on the abscissa. The distribution of products associated with $\mathrm{NH}_{3}$ production is shown on the right. The conversion of glutamine to glucose, lactate, pyruvate, and amino acids is associated with the production of both ammonia and $\mathrm{CO}_{2}$. In Fig. 4 the ammonia produced in association with this $\mathrm{CO}_{2}$ is already accounted for by the conversion to these products. Accordingly, the ammonia predicted to be produced in association with the conversion of glutamine to ${ }^{14} \mathrm{CO}_{2}$ is calculated from the total ${ }^{14} \mathrm{CO}_{2}$ production minus the ${ }^{14} \mathrm{CO}_{2}$ calculated to be produced in association with the conversion of glutamine to

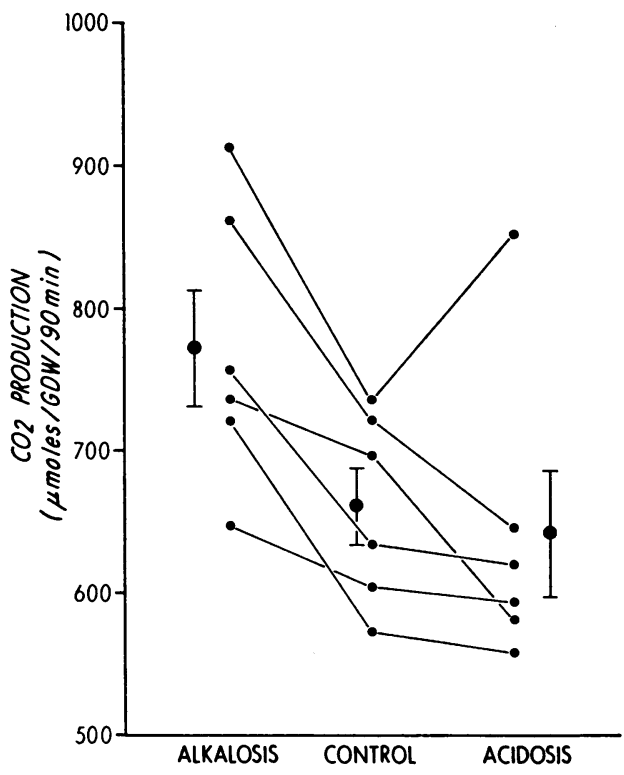

FIGURE 3 The effect of in vivo acid-base status on the conversion of $1,2-{ }^{14} \mathrm{C}$-acetate to ${ }^{14} \mathrm{CO}_{2}$. Each point represents 3-6 observations on ${ }^{14} \mathrm{CO}_{2}$ production by cortex slices from different animals. Also, shown is the mean $\pm \mathrm{SE}$ for all observations with alkalotic $(n=26)$, control $(n=27)$, and acidotic $(n=24)$ animals.

other products. If predicted and observed $\mathrm{NH}_{3}$ production were the same, the top of each column would fall on the line of identity.

As shown in the Fig. 4, predicted ammonia production is about $200-250 \mu$ moles greater than the observed ammonia production. Predicted ammonia may exceed observed ammonia for several reasons. Endogenous substrates containing no nitrogen may be converted to glucose, lactate, etc., without resulting in ammonia production. Conversely, glutamine converted to the products used to predict ammonia production may have donated its nitrogen to products not determined in these studies. The slope for the regression of predicted on observed ammonia production is close to one. This indicates that we are probably measuring all of the major products of glutamine metabolism in renal cortex slices associated with the change in ammonia production that occurs as a result of acidosis.

The data shown in Fig. 4 and Table I indicate that the products of glutamine metabolism, significantly affected by prior acid-base status, which could be associated with increased $\mathrm{NH}_{3}$ production are glucose, lactate, pyruvate, lipid, protein, and glutamate. In Table III we have examined the extent to which the increased conversion of glutamine to these products can account for the enhanced $\mathrm{CO}_{2}$ and ammonia production found during acidosis. The upper part of Table III shows the effect of acidosis on the conversion of glutamine to 


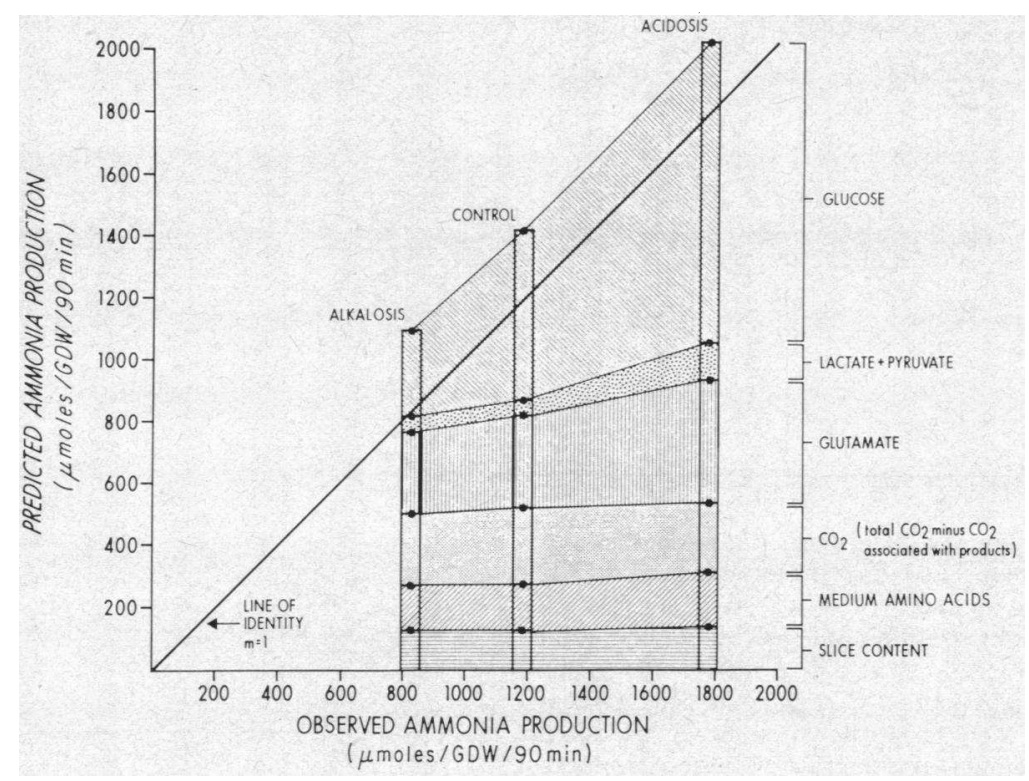

FIGURE 4 Relation between predicted and observed ammonia production. The predicted ammonia production, based on the conversion of glutamine to other products, is shown on the vertical axis and graphed for the studies with slices from alkalotic, control and acidotic animals. The distribution of products associated with ammonia production is shown on the right. The observed ammonia production during these studies is plotted on the horizontal axis (see text for details).

TABLE III

A Comparison of the Observed $\triangle \mathrm{CO}_{2}$ and $\Delta \mathrm{NH}_{3}$ following Acidosis and the Predicted $\mathrm{\Delta CO} \mathrm{O}_{2}$ and $\Delta \mathrm{NH}_{3}$, Based on the Changes in Glutamine and Glutamate Conversion to Other Products

\begin{tabular}{|c|c|c|c|c|c|c|}
\hline & \multicolumn{3}{|c|}{ Acidosis minus control } & \multicolumn{3}{|c|}{ Acidosis minus alkalosis } \\
\hline & \multirow{2}{*}{$\frac{\text { Observed }}{\Delta \text { Products }}$} & \multicolumn{2}{|c|}{ Predicted } & \multirow{2}{*}{$\frac{\text { Observed }}{\Delta \text { Products }}$} & \multicolumn{2}{|c|}{ Predicted } \\
\hline & & $\Delta \mathrm{CO}_{2}$ & $\Delta \mathrm{NH}_{3}$ & & $\Delta \mathrm{CO}_{2}$ & $\Delta \mathrm{NH}_{\mathbf{3}}$ \\
\hline 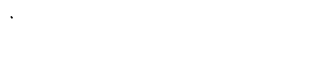 & $\begin{array}{c}\text { Amoles of prod/ } \\
G D W\end{array}$ & $\begin{array}{c}\text { Mmoles of subst/ } \\
G D W\end{array}$ & Mmoles $/ G D W$ & $\begin{array}{c}\text { Mmoles of prod/ } \\
\text { GDW }\end{array}$ & $\begin{array}{c}\text { Mmoles of subst/ } \\
G D W\end{array}$ & umoles/GDW \\
\hline \multicolumn{7}{|l|}{ Glutamine studies } \\
\hline Glucose & 105 & 84 & 420 & 171 & 137 & 684 \\
\hline Lactate + pyruvate & 32 & 13 & 64 & 37 & 15 & 74 \\
\hline Lipid & 1* & 2 & 3 & $2 *$ & 3 & 10 \\
\hline Protein & $5 *$ & 1 & 6 & 6* & 2 & 8 \\
\hline Glutamate & 111 & $\mathbf{0}$ & 111 & 138 & $\mathbf{0}$ & 138 \\
\hline Predicted total $\Delta$ & & 100 & 604 & & 157 & 914 \\
\hline Observed total $\Delta$ & & 93 & 593 & & 161 & 962 \\
\hline Observed $\Delta /$ predicted $\Delta$ & & 0.93 & 0.98 & & 1.02 & 1.05 \\
\hline \multicolumn{7}{|l|}{ Glutamate studies } \\
\hline Glucose & 50 & 40 & 100 & 96 & 76 & 192 \\
\hline Lactate + pyruvate & 9 & 4 & 9 & 13 & 5 & 13 \\
\hline Lipid & $2 *$ & 3 & 5 & $2 *$ & 3 & 5 \\
\hline Protein & $1^{*}$ & $\mathbf{0}$ & $\mathbf{0}$ & 0 & 0 & $\mathbf{0}$ \\
\hline Glutamine & -30 & $\mathbf{0}$ & 30 & -158 & $\mathbf{0}$ & 158 \\
\hline Predicted total $\Delta$ & & 47 & 144 & & 84 & 368 \\
\hline Observed total $\Delta$ & & 34 & 117 & . & 52 & 253 \\
\hline Observed $\Delta /$ predicted $\Delta$ & & 0.72 & 0.81 & & 0.62 & 0.69 \\
\hline
\end{tabular}

* Expressed as $\mu$ moles of substrate in product. 
these products when compared with their production by slices from control ( $\Delta$ acid - cont) and alkalotic animals ( $\Delta$ acid - alk). The $\Delta \mathrm{NH}_{3}$ and $\Delta \mathrm{CO}_{2}$ predicted from the change in conversion to these products is also given. It can be seen that the ratio of observed: predicted ${ }^{14} \mathrm{CO}_{2}$ and ammonia production is close to one when ${ }^{14} \mathrm{CO}_{2}$ and ammonia production from glutamine in slices from acidotic animals is compared with that found in slices from either control ( $\Delta$ acid - cont) or alkalotic animals ( $\Delta$ acid - alk).

Relation betwcen ammonia and $\mathrm{CO}_{2}$ production from glutamate and its conversion to other products. As shown in Table I, the products of glutamate metabolism, other than ammonia and ${ }^{14} \mathrm{CO}_{2}$, which changed significantly as a result of acidosis were glucose, lactate, lipid, protein, and glutamine. In the lower part of Table III, the change in glutamate conversion to these products, and to ammonia and ${ }^{14} \mathrm{CO}_{2}$ after acidosis, has been analyzed in the same manner as that described in the previous section for the glutamine studies. In this analysis a decrease in glutamine production from glutamate is assumed to predict an equimolar increase in $\mathrm{NH}_{3}$ production. The data indicate that the observed change in the conversion of glutamate to the products shown after acidosis, more than accounted for the observed increases in $\mathrm{NH}_{3}$ and ${ }^{14} \mathrm{CO}_{2}$ production. As was suggested for the glutamine studies shown in Fig. 4, this finding may be due to conversion of endogenous substrates, which do not give rise to ammonia, to the products shown in Table III, or to the conversion of glutamate to these products and nitrogen containing products other than ammonia, which were not determined in these studies. Another possibility, suggested by the data shown in Fig. 3, is that following acidosis a decrease in the complete oxidation of glutamate to $\mathrm{CO}_{2}$ and ammonia occurs.

Relation between the conversion of glutamate to glutamine and its conversion to glucose, lactate, and ammonia. In the glutamate studies, glucose, lactate, ${ }^{14} \mathrm{CO}_{2}$, and $\mathrm{NH}_{\mathbf{s}}$ production increased significantly after acidosis. Since acidosis did not enhance glutamate uptake, the increase in glucose, lactate, ${ }^{14} \mathrm{CO}_{2}$, and ammonia production can only be accounted for by a decrease in the conversion of glutamate to other products. It is apparent from Tables I and III that glutamine is the major product of glutamate metabolism which decreases after acidosis. As shown in the lower part of Table III ( $\Delta$ acid alk) the increase in glucose and lactate production after acidosis was 96 and $13 \mu$ moles, respectively. Since 2 $\mu$ moles of glutamate are required to produce $1 \mu$ mole of glucose, this indicates that an additional $205 \mu$ moles of glutamate were converted to these products as a result of acidosis. This diversion of glutamate to glucose and lactate during acidosis may, by making less glutamate available, explain the quantitatively similar decrease in conversion of glutamate to glutamine of $158 \mu$ moles (Table III, $\Delta$ acid - alk). An alternate explanation, not ruled out by these studies, is that the primary event in acidosis is a net decrease in glutamine production from glutamate which secondarily leads to increased conversion of glutamate to glucose, lactate, $\mathrm{CO}_{2}$, and ammonia.

\section{DISCUSSION}

These studies demonstrate that in renal cortex slices there is a marked dependence of glutamine metabolism, and to a lesser extent glutamate metabolism, on prior acid-base status. When compared with slices from alkalotic animals, slices from acidotic animals demonstrated a twofold increase in glutamine uptake. Glutamate uptake, on the other hand, was not significantly affected by prior acidosis or alkalosis. Although acid-base status did not affect glutamate uptake, it markedly influenced its metabolic fate. In the absence of changes in glutamate uptake, it must be concluded that acid-base status alters the intracellular metabolism of glutamate. A1though an effect of acid-base status on glutamine transport into cells is not ruled out by these studies, the effects of acid-base status on glutamate metabolism suggests that the increase in $\mathrm{NH}_{3}$ production from glutamine during acidosis is at least in part related to changes in its intracellular metabolism.

The data summarized in Fig. 4 indicate that all of the major products of glutamine metabolism associated with $\mathrm{NH}_{3}$ production in rat renal cortex slices were determined in the present studies. They confirm our previous observation (32) that about three-quarters of the increment in $\mathrm{NH}_{3}$ production from glutamine in rat renal cortex after acidosis can be accounted for by increased glucose production, and demonstrate that the remaining one-fourth can be explained by enhanced conversion of glutamine to lactate, pyruvate, lipid, protein, and glutamate. These experiments also indicate that most of the increase in glucose production as a result of acidosis was derived from glutamine, since the rise in glucose production determined from the incorporation of $\mathrm{U}_{-}{ }^{14} \mathrm{C}$ glutamine into glucose can account for $85 \%$ of the increase in glucose production determined with glucose oxidase.

With slices from control animals, glutamine uptake exceeded that of glutamate by $303 \mu$ moles/g dry weight per $90 \mathrm{~min}$, an amount approximately equal to, and presumably explained by the conversion of glutamine to glutamate (Table I). The fourfold greater ammonia production from glutamine when compared to glutamate (control studies, Table I) can also be explained in terms of the products summarized in Table I. The metabolism of glutamine to nonnitrogen containing products would result in twice as much ammonia as would the metabolism of a similar amount of glutamate. In addi- 
tion, ammonia production is increased to the extent that glutamine is converted to glutamate. Conversely, with glutamate as substrate, conversion to glutamine reduces ammonia production.

Glucose and lactate production from glutamine was similar to that from glutamate when the metabolism of slices from control animals was examined. After acidosis however the increase in glucose and lactate production from glutamine was 171 and $37 \mu$ moles/g dry weight per $90 \mathrm{~min}$, respectively (Table III, $\Delta$ acid - alk). These values are significantly greater $(P<0.01)$ than the increase in glucose and lactate production of 96 and 13 $\mu$ moles which occurred from glutamate after acidosis (Table III, $\Delta$ acid - alk). The mechanism of the greater effect of acidosis on glutamine metabolism is not apparent from these studies. Possible explanations are: $(a)$ stimulation by acidosis of glutamine transport but not of glutamate transport into kidney cells, and $(b)$ increased glutamine metabolism along pathways, such as the glutamine transaminase- $\Omega$-amidase pathway, in which glutamate is not an intermediate.

The conversion of glutamate to glutamine was increased by alkalosis and decreased by acidosis. These observations are consistent with the studies of Damian and Pitts (6) in which alkalosis increased glutamine synthetase activity and decreased glutaminase I activity in vivo in the rat kidney. They concluded that glutaminase I and glutamine synthetase are influenced by acidbase status in opposite ways and form an operationally reversible system which acts to control renal ammonia production. Increased net glutamine synthesis during alkalosis could, by decreasing glutamate concentration, make it less available for conversion to glucose and lactate. It is also possible that acidosis primarily stimulates glutamate conversion to glucose and lactate and that this subsequently leads to decreased glutamate availability for glutamine synthesis. By either mechanism, ammonia production would be decreased during alkalosis, both by reduced conversion of glutamate to glucose, lactate, $\mathrm{CO}_{2}$, and ammonia, and because of increased conversion of free ammonia and glutamate to glutamine.

Simpson and Sherrard (9) have demonstrated that the conversion of $\mathrm{U}_{-}{ }^{14} \mathrm{C}$-glutamine to ${ }^{14} \mathrm{CO}_{2}$ is increased in renal cortical slices from acidotic dogs and in cortical slices from normal dogs incubated at a reduced medium $\mathrm{pH}$. They suggest that during acidosis, increased glutamine utilization, presumably in mitochondria, leads to enhanced conversion of glutamine to ammonia and $\mathrm{CO}_{2}$. Our experiments suggest that in renal cortex from acidotic rats, increased ${ }^{14} \mathrm{CO}_{2}$ production from $\mathrm{U}_{-}{ }^{14} \mathrm{C}$-glutamine is not secondary to stimulation of the complete oxidation of glutamine. Rather, it appears to be related to an acidosis-stimulated conversion of glutamine to glucose, lactate, pyruvate and lipid, products associated with obligatory $\mathrm{CO}_{2}$ production when they are derived from glutamine. The conversion of $1,2-{ }^{14} \mathrm{C}$-acetate to ${ }^{14} \mathrm{CO}_{2}$ was increased by alkalosis, and appeared to be decreased by acidosis. Nagata and Rasmussen (10) have found ${ }^{14} \mathrm{CO}_{2}$ production from both $1{ }^{14} \mathrm{C}$-pyruvate and $2-{ }^{14} \mathrm{C}$-pyruvate to be decreased when isolated renal cortical tubules from normal rats were incubated at a reduced medium $\mathrm{pH}$. These studies of acetate and pyruvate metabolism suggest, but do not prove, that in rat renal cortex, acetyl CoA entry into the Krebs cycle is decreased by acidosis. The increase in phosphoenolpyruvate carboxykinase activity known to be present in renal cortex from acidotic rats is a possible explanation for these observations on ${ }^{14} \mathrm{CO}_{2}$ production. Stimulation of oxalacetate conversion to phosphoenolpyruvate during acidosis would limit the complete oxidation of glutamine and glutamate in the Krebs cycle and make less oxalacetate available for a combination with acetyl CoA. In a previous study Goorno, Rector, and Seldin (33) found ${ }^{14} \mathrm{C}$-acetate conversion to ${ }^{14} \mathrm{CO}_{2}$ by rat renal cortex to be unaffected by acid-base status. The data presented by Goorno et al. are based on studies with renal cortical slices from three acidotic and three alkalotic animals. The difference in our results may therefore be related to the limited number of observations employed by these investigators. As shown in Fig. 3, the effect of acidbase status on $1,2-{ }^{14} \mathrm{C}$-acetate conversion to ${ }^{14} \mathrm{CO}_{2}$ was small in several experiments. A significant increase after alkalosis was only apparent when experiments were combined.

The effects of acid-base status on renal glutamine metabolism have also been examined by Pilkington and O'Donovon (34). These investigators found the conversion of glutamine to $\mathrm{CO}_{2}$ to be increased to a greater extent than could be accounted for by the changes in glucose production when dog renal cortical slices were incubated at a reduced $\mathrm{pH}$. Since our experiments were performed with rat renal cortex, and evaluated the effects of acidosis or alkalosis produced in vivo over a $48 \mathrm{hr}$ period, a direct comparison with their studies is not possible. Renal cortical metabolism in the dog is different in several respects from that found in the rat. In the rat kidney glutamine synthetase activity in vivo (6), and glutaminase I activity in vivo (6) and in vitro (35), vary significantly during changes in acid-base status. In the dog kidney however adaptation of glutaminase I does not occur during acidosis (36) and glutamine synthetase is not detectable either in vivo (37) or in vitro (38). In addition, glucose production from $10 \mathrm{~mm}$ glutamine in rat renal cortex is about fivefold that found in dog renal cortex $(32,34)$.

Since $\mathrm{O}_{2}$ utilization and total $\mathrm{CO}_{2}$ production were not determined in the present experiments, these studies do not critically evaluate the effects of acid-base status on 
total Krebs cycle activity. Previous studies of $\mathrm{O}_{2}$ utilization and $\mathrm{CO}_{2}$ production in the literature present conflicting results. Okabe and Kodama (39) determined the $\mathrm{O}_{2}$ utilization and $\mathrm{CO}_{2}$ production of rabbit renal cortex slices incubated in Ringers-bicarbonate medium. They found both parameters to increase when medium $\mathrm{pH}$ was increased from 7.4 to 7.8 , and to decrease when medium $\mathrm{pH}$ was reduced to 7.0. Cohen (40) has examined gas metabolism across the dog kidney in vivo. In his studies acidosis significantly decreased $\mathrm{CO}_{2}$ production, but did not effect $\mathrm{O}_{2}$ utilization. In other studies, Preuss (41) has found increased $\mathrm{O}_{2}$ utilization when isolated dog renal tubules were incubated at a reduced medium $\mathrm{pH}$. Because of species differences and variation in the experimental technique none of these studies are directly comparable with our experiments.

Phosphoenolpyruvate is a precursor of glucose, pyruvate, lactate, and lipid synthesis. Increased PEP-carboxykinase activity therefore is a possible explanation for the increased conversion of glutamine to these products which was found in our studies with slices from acidotic animals. The only major product of glutamine metabolism stimulated by acidosis which cannot be explained in terms of PEP-carboxykinase activity is glutamate. Increased conversion of glutamine to glutamate during acidosis may be related to the changes in glutaminase I and glutamine synthetase activity described above. It is also possible that the production of glutamate in large amounts is an artifact of our experimental protocol in which kidney slice metabolism is examined in the presence of high concentrations of glutamine. There is no evidence that acidosis increases the conversion of glutamine to glutamic acid in the kidney in vivo $(2,3)$.

The present experiments demonstrate a quantitative relation between ammonia production from glutamine and the conversion of glutamine to products associated with PEP-carboxykinase activity. They do not however, establish that a cause and effect relation between PEPcarboxykinase activity and ammonia production is present. Recent studies by Pagliara and Goodman (42) and Preuss (14) have demonstrated a dissociation between glucose and ammonia production by renal cortex slices when incubations are carried out at various $\mathrm{pHs}$. In addition, Simpson and Sherrard (9) have found $\mathrm{pH}$ effects on glutamine metabolism in mitochondria despite the fact that PEP-carboxykinase is located primarily in the cytoplasm (13). Although the present experiments do not provide evidence that PEP-carboxykinase is a primary regulator of renal ammonia production, they suggest that changes in its activity may be an important part of the response of renal cortex to acidosis.

The effect of medium $\mathrm{pH}$ on hepatic glutamine and glutamate metabolism has recently been examined by Lueck and Miller in the isolated perfused rat liver (43).
Livers perfused at $\mathrm{pH} 7.15$ had decreased glutamine utilization and conversion to $\mathrm{CO}_{2}$ when compared with livers perfused at $\mathrm{pH}$ 7.45. Although these results are opposite those found with renal cortex slices in the present experiments, they are not completely unexpected since it has previously been demonstrated that liver and kidney metabolism respond differently to changes in acid-base status (44). The effects of acid-base status on glutamate metabolism however, appear to be similar in liver and kidney. In both our studies, and in those of Lueck and Miller, glutamate uptake and conversion to $\mathrm{CO}_{2}$ were relatively unaffected by $\mathrm{pH}$. In addition, in both tissues glutamate conversion to glutamine appears to be enhanced by alkalosis.

\section{APPENDIX}

Studies performed to determine the correction factor for gas phase $\mathrm{CO}_{2}$

Slices from four acidotic, four control; and four alkalotic rats were incubated at $37^{\circ} \mathrm{C}$ for $90 \mathrm{~min}$ in $10 \mathrm{ml}$ of KrebsRinger bicarbonate buffer containing $10 \mathrm{~mm}$ glutamine (12 flasks) and $10 \mathrm{~mm}$ glutamate (12 flasks). At the end of incubation, determinations for medium $\mathrm{P}_{\mathrm{CO}_{2}}$ and total $\mathrm{CO}_{2}$ were made on samples obtained anaerobically. Total $\mathrm{CO}_{2}$ was determined with a Natelson microgasometer and $\mathrm{P}_{\mathrm{CO}_{2}}$ using a Radiometer $\mathrm{P}_{\mathrm{CO}_{2}}$ electrode and $\mathrm{pH}$ Meter 27. Flask volume was determined by weighing the stoppered flasks before and after the addition of distilled water. Separate factors were calculated to determine gas phase $\mathrm{CO}_{2}$ for studies with slices from acidotic, control, and alkalotic rats using the following equations:

$$
\text { Medium } \mathrm{H}_{2} \mathrm{CO}_{3}(\mu \text { moles } / \mathrm{ml})=0.03 \mathrm{P}_{\mathrm{CO}_{2}}
$$

Gas phase $\mathrm{CO}_{2}(\mu$ moles/flask $)$

$$
=\frac{\text { total flask volume }(\mathrm{ml})-10 \mathrm{ml} \times \mathrm{P}_{\mathrm{CO}_{2}} / 760}{0.0254 \mathrm{ml} / \mu \mathrm{mole}}
$$

\section{Correction factor}

$$
\begin{aligned}
& \text { medium total } \mathrm{CO}_{2} / \text { flask } \\
& =\frac{+ \text { gas phase } \mathrm{CO}_{2} / \text { flask }}{\text { medium total } \mathrm{CO}_{2} / \text { flask }} \\
& \text { - medium } \mathrm{H}_{2} \mathrm{CO}_{3} / \text { flask }
\end{aligned}
$$

Sample calculation:

Medium total $\mathrm{CO}_{2}=25.5 \mu$ moles $/ \mathrm{ml}$

Medium $\mathrm{P}_{\mathrm{CO}_{2}}=38 \mathrm{~mm} \mathrm{Hg}$

Total flask volume $=55.5 \mathrm{ml}$

$$
\text { Gas phase } \begin{aligned}
\mathrm{CO}_{2} & =\frac{(55.5 \mathrm{ml}-10 \mathrm{ml}) \times \frac{38}{760}}{0.0254 \mathrm{ml} / \mu \text { mole }} \\
& =89.6 \mu \text { moles } / \text { flask }
\end{aligned}
$$


Correction factor

$$
\begin{aligned}
& =\frac{255 \mu \text { moles } / 10 \mathrm{ml}+89.6 \mu \text { moles }}{255 \mu \text { moles }-10(0.03 \times 38)} \\
& =1.42
\end{aligned}
$$

In an experimental sample in which the dry weight of tissue in the flask was $25.3 \mathrm{mg}$ and the conversion of glutamine to $\mathrm{CO}_{2}$ determined with $\mathrm{U}_{-}{ }^{14} \mathrm{C}$-glutamine was 0.61 umoles/ml of medium :

$\mathrm{CO}_{2}$ production from glutamine

$$
\begin{aligned}
& =1.42 \frac{0.61 \mu \text { moles } / \mathrm{ml} \times 10}{0.0253 \mathrm{~g}} \\
& =342 \mu \text { moles } / \mathrm{g} \text { dry weight }
\end{aligned}
$$

Equation $\mathrm{A} 3$ assumes that when experimental samples are analyzed, all of the medium $\mathrm{H}_{2} \mathrm{CO}_{3}$ (free $\mathrm{CO}_{2}$ ) is lost when the flask is opened and the sample pipetted. In practice only part of the medium $\mathrm{H}_{2} \mathrm{CO}_{3}$ is lost. If none of the $\mathrm{H}_{2} \mathrm{CO}_{3}$ were lost the calculated flask $\mathrm{CO}_{2}$ would be $5 \%$ higher than the true flask $\mathrm{CO}_{2}$. This probably accounts in part for the greater than $100 \%$ recovery observed in our control studies.

\section{ACKNOWLEDGMENTS}

We wish to thank Mrs. Barbara Kuchmy and Mrs. Suzanne Till for their technical assistance, Miss Diane McCauley for preparation of the manuscript, and Doctors Leon L. Miller and Julius J. Cohen for their review of the manuscript.

This study was supported by grant AM 11023 from the National Institutes of Health.

\section{REFERENCES}

1. Van Slyke, D. D., R. A. Phillips, P. B. Hamilton, R. M. Archibald, P. H. Futcher, and A. Hiller. 1943. Glutamine as source material of urinary ammonia. J. Biol. Chem. 150: 481 .

2. Owen, E. E., and R. R. Robinson. 1963. Amino acid extraction and ammonia metabolism by the human kidney during the prolonged administration of ammonium chloride. J. Clin. Invest. 42: 263.

3. Shalhoub, R., W. Webber, S. Glabman, M. CanessaFischer, J. Klein, J. de Haas, and R. F. Pitts. 1963. Extraction of amino acids from and their addition to renal blood plasma. Amer. J. Physiol. 204: 181.

4. Stone, W. J., S. Balagura, and R. F. Pitts. 1967. Diffusion equilibrium for ammonia in the kidney of the acidotic dog. J. Clin. Invest. 46: 1603.

5. Churchill, P. C., and R. L. Malvin. 1970. Relation of renal gluconeogenesis to ammonia production in the dog. Amer. J. Physiol. 218: 241.

6. Damian, A. C., and R. F. Pitts. 1970. Rates of glutaminase $I$ and glutamine synthetase reactions in rat kidney in vivo. Amer. J. Physiol. 218: 1249.

7. Stone, W. J., and R. F. Pitts. 1967. Pathways of ammonia metabolism in the intact functioning kidney of the dog. J. Clin. Invest. 46: 1141.

8. Alleyne, G. A. O. 1970. Renal metabolic response to acid-base changes. II. The early effects of metabolic acidosis on renal metabolism in the rat. J. Clin. Invest. 49 : 943.
9. Simpson, D. P., and D. J. Sherrard. 1969. Regulation of glutamine metabolism in vitro by bicarbonate ion and $\mathrm{pH}$. J. Clin. Invest. 48: 1088.

10. Nagata, N., and H. Rasmussen. 1970. Renal gluconeogenesis: effects of $\mathrm{Ca}^{2+}$ and $\mathrm{H}^{+}$. Biochim. Biophys. Acta. 215: 1 .

11. Goodman, A. D., R. E. Fuisz, and G. F. Cahill, Jr. 1966. Renal gluconeogenesis in acidosis, alkalosis, and potassium deficiency: its possible role in regulation of renal ammonia production. J. Clin. Invest. 45: 612 .

12. Goldstein, L. 1966. Relation of glutamate to ammonia production in rat kidney. Amer. J. Physiol. 210: 661.

13. Alleyne, G. A. O., and G. H. Scullard. 1969. Renal metabolic response to acid base changes. I. Enzymatic control of ammoniagenesis in the rat. J. Clin. Invest. 48: 364 .

14. Preuss, H. G. 1969. Renal glutamate metabolism in acute metabolic acidosis. Nephron. 6: 235.

15. Preuss, H. G. 1968. Pyridine nucleotides in renal ammonia metabolism. J. Lab. Clin. Med. 72: 370.

16. Kamm, D. E., R. E. Fuisz, A. D. Goodman, and G. F. Cahill, Jr. 1967. Acid-base alterations and renal gluconeogenesis: effect of $\mathrm{pH}$, bicarbonate concentration and

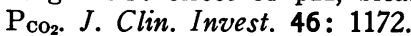

17. White, H. H. 1968. Separation of amino acids in physiologic fluids by two-dimentional thin-layer chromatography. Clin. Chim. Acta. 21: 297.

18. Whereat, A. F., D. R. Snydman, and L. A. Barness. 1968. Thin-layer chromatography of citric acid cycle intermediates, pyruvate and lactate. J. Chromatog. 36: 390.

19. Weil-Malherbe, H., and H. A. Krebs. 1935. CCXLVI. Metabolism of aminoacids. V. The conversion of proline into glutamic acid in kidney. Biochem. J. 29: 2077.

20. Hugget, A. St. G., and D. A. Nixon. 1957. Use of glucose oxidase, peroxidase and 0-dianisidine in determination of blood and urinary glucose. Lancet. 2: 368 .

21. Bucher, T., R. Czok, W. Lamprecht, and E. Latzko. 1965. Pyruvate. In Methods of Enzymatic Analysis. H. U. Bergmeyer, editor. Academic Press, Inc., New York. 2nd printing, revised. 253.

22. Hohorst, H. J. 1965. Lactate. In Methods of Enzymatic Analysis. H. U. Bergmeyer, editor. Academic Press, Inc., New York. 2nd printing, revised. 266.

23. Conway, E. J. 1947. Microdiffusion Analysis and Volumetric Error. Crosby Lockwood, London. 2nd edition.

24. Graham, L. T., R. Werman, and M. H. Aprison. 1965. Microdetermination of glutamate in single cat spinal roots. Life Sci. 4 : 1085.

25. Addae, S. K., and W. D. Lotspeich. 1968. Relation betwen glutamine utilization and production in metabolic acidosis. Amer. J. Physiol. 215: 269.

26. Pfleiderer, G. 1965. Glutamate. In Methods of Enzymatic Analysis. H. U. Bergmeyer, editor. Academic Press, Inc. New York. 2nd printing, revised. 396.

27. Gupta, G. H. 1966. A simple in-vial combustion method for assay of hydrogen-3, carbon-14, and sulfur-35 in biological, biochemical, and organic material. Anal. Chem. 38: 1356.

28. Folch, J., M. Lees, and C. H. Sloane-Stanley. 1957. A simple method for the isolation and purification of total lipids from animal tissues. J. Biol. Chem. 226: 497.

29. Bignall, M. C., O. Elebute, and W. D. Lotspeich. 1968. Renal protein and ammonia biochemistry in $\mathrm{NH}_{4} \mathrm{Cl}$ acidosis and after nephrectomy. Amer. J. Physiol. 215: 289. 
30. Lowry, O. H., N. J. Rosebrough, A. L. Farr, and R. J. Randall. 1951. Protein measurement with the Folin phenol reagent. J. Biol. Chem. 193: 265.

31. West, E. S., W. R. Todd, H. S. Mason, and J. T. Van Bruggen. 1966. Textbook of Biochemistry. The Macmillan Company, New York. 4th edition. 262.

32. Kamm, D. E., and R. R. Asher. 1970. Relation between glucose and ammonia production in renal cortical slices. Amer. J. Physiol. 218: 1161.

33. Goorno, W. E., F. C. Rector, Jr., and D. W. Seldin. 1967. Relation of renal gluconeogenesis to ammonia production in the dog and rat. Amer. J. Physiol. 213: 969.

34. Pilkington, L. A., and D. J. O'Donovan. 1971. Metabolism of glutamine in cortex slices from dog kidney during acid-base alterations. Amer. J. Physiol. 220: 1634.

35. Rector, F. C., Jr., D. W. Seldin, and J. H. Copenhaver 1954. The mechanism of ammonia excretion during ammonium chloride acidosis. J. Clin. Invest. 34: 20.

36. Rector, F. C., Jr., and J. Orloff. 1959. The effect of the administration of sodium bicarbonate and ammonium chloride on the excretion and production of ammonia. The absence of alterations in the activity of renal ammonia-producing enzymes in the dog. J. Clin. Invest. $38: 366$.
37. Lyon, M. L., and R. F. Pitts. 1969. Species differences in renal glutamine synthesis in vivo. Amer. J. Physiol. $216: 117$.

38. Krebs, H. A. 1935. CCXXX. Metabolism of aminoacids. IV. The synthesis of glutamine from glutamic acid and ammonia, and the enzymic hydrolysis of glutamine in animal tissues. Biochem. J. 29: 1951.

39. Okabe, T., and S. Kodama. 1934. Studies on gas metabolism of tissue in vitro. VII. Tohoku. J. Exp. Med. 23: 273.

40. Cohen, J. J. 1960. High respiratory quotient of dog kidney in vivo. Amer. J. Physiol. 199: 560.

41. Preuss, H. G. 1971. Ammonia production from glutamine and glutamate in isolated dog renal tubules. Amer. J. Physiol. 220: 54.

42. Pagliara, A. S., and A. D. Goodman. 1970. Relation of renal cortical gluconeogenesis, glutamate content, and production of ammonia. J. Clin. Invest. 49: 1967.

43. Lueck, J. D., and L. L. Miller. 1970. The effect of perfusate $\mathrm{pH}$ on glutamine metabolism in the isolated perfused rat liver. J. Biol. Chem. 245: 5491

44. Kamm, D. E., and G. F. Cahill, Jr. 1969. Effect of acidbase status on renal and hepatic gluconeogensis in diabetes and fasting. Amer. J. Physiol. 216: 1207. 